\title{
The effect of verbalization strategy on wisconsin card sorting test performance in schizophrenic patients receiving classical or atypical antipsychotics
}

\author{
Alessandro Rossi*1, Enrico Daneluzzo ${ }^{1}$, Annarita Tomassini ${ }^{1}$, \\ Francesca Struglia ${ }^{1}$, Roberto Cavallaro ${ }^{2}$, Enrico Smeraldi ${ }^{2}$ and Paolo Stratta ${ }^{3}$
}

Address: ${ }^{1}$ Department of Experimental Medicine, University of L'Aquila, Italy, ${ }^{2}$ Department of Neuroscience, Libera Università "Vita Salute S.Raffaele" Milano, Italy and ${ }^{3}$ Department of Mental Health, A.U.S.L. 4 L'Aquila, Italy

Email: Alessandro Rossi* - alessandro.rossi@cc.univaq.it; Enrico Daneluzzo - cim.alba@asl18.sanitacn.it; Annarita Tomassini - annaritatomassini@yahoo.it; Francesca Struglia - francescastruglia@hotmail.com; Roberto Cavallaro - cavallaro.roberto@hsr.it; Enrico Smeraldi - smeraldi@hsr.it; Paolo Stratta - psystr@tin.it

* Corresponding author

Published: 26 January 2006

BMC Psychiatry 2006, 6:3 doi:10.1186/147I-244X-6-3
Received: 19 July 2005

Accepted: 26 January 2006

This article is available from: http://www.biomedcentral.com/l47I-244X/6/3

(c) 2006 Rossi et al; licensee BioMed Central Ltd.

This is an Open Access article distributed under the terms of the Creative Commons Attribution License (http://creativecommons.org/licenses/by/2.0), which permits unrestricted use, distribution, and reproduction in any medium, provided the original work is properly cited.

\begin{abstract}
Background: A number of reports showed en encouraging remediation in some patients' executive deficits thanks to the use of 'information processing strategies'. Moreover the impact of antipsychotics on cognitive functions of the schizophrenics is an important issue, especially if an integrated psychosocial treatment is needed.

The aim of this paper is to evaluate different executive performance and response to verbalization, a strategy of the Wisconsin Card Sorting Test (WCST) remediation, in subjects on classical vs atypical antipsychotic (AP) treatment.

Methods: Sixty-three schizophrenic subjects undertook the WCST under standard and modified (verbalization) administration. Subjects were stratified by the kind of WCST response (i.e. good, poor and remediable) and AP treatment (i.e. atypical vs. classical).

Results: Subjects on atypical APs showed a better performance than those on classical ones. More poor performers who did not remediate were seen in the sample with classical Aps while subjects who remediated the performance were seen in the subgroup with atypical APs only. An increase of perseverative and total errors was seen in poor performers subjects on classical APs.

Conclusion: Subjects on atypicals showed a better cognitive pattern in terms of WCST performance. Since the naturalistic assignment of medication we cannot draw conclusions about its effect on cognitive performance and its interaction with cognitive remediation potential. However the data lead us to hypothesize that subjects with potential room for remediation did so with the atypical APs.
\end{abstract}

\section{Background}

Cognitive deficits are important targets for intervention in patients with schizophrenia to favor clinical and functional success. Executive skills are relevant for dealing 
with novel and complex situations, crucial for occupational outcome and independent living of people with schizophrenia $[1,2]$. Several studies reported that a large part of these people improve their executive performance by remediation strategies and cognitive therapies [3-5].

A number of reports showed en encouraging remediation in some patients' executive deficits thanks to the use of 'information processing strategies'. This has been mostly investigated using Wisconsin Card Sorting Test (WCST), and verbalization has been found the most efficacious procedure to obtain the performance improvement. Cumulatively, these data suggest that a simple instruction may enhance executive function and affect WCST performance in patients with schizophrenia [6-9].

In our previous studies on remediation of WCST performance of persons with schizophrenia we hypothesised that the improvement could be attained through a cognitive strategy that bounds schizophrenic patients to use a conceptually driven processing. Using verbalization as such a strategy, we observed that when the patients were required to verbally express the matching criterion before the card sorting, a remediation of the poor WCST response occurred $[10,11]$. Furthermore, we observed different patterns of response to verbalization, i.e. improvement or worsening of the performance. About the 63\% of the WCST poor performers improved while the remaining patients, showed an increase of perseverative errors. The latter subjects were characterized by more negative symptoms, poor outcome and earlier age at onset. On the basis of these observations we hypothesized that this modified WCST administration could be used as a criterion that, if validated, could be able to unveil different patient subgroup with different pathophysiological trajectories.

The impact of antipsychotics (APs) on cognitive functions of the schizophrenics is an important issue, especially if an integrated psychosocial treatment is needed [2]. Even though cognitive enhancement in schizophrenia is far from being a resolved issue [12], there is evidence that atypical APs can provide some cognitive benefit (for reviews see $[1,13]]$. However, caution is needed before generalize the results of these studies because the limited effect size and deficient methodologies [13].

The aim of this study is to compare the cognitive performance and response to verbalization in subjects on classical vs atypical APs.

\section{Methods \\ Subjects}

A sample of 63 consecutive out-patients (18 females and 45 males) who met the DSMIII-R criteria for schizophrenia were evaluated cross-sectionally along a naturalistic perspective. Diagnoses were made by a senior psychiatrist (P.S.) who personally interviewed the patients according to the Structured Clinical Interview for DSM-III-R [14]. The subjects were excluded if had history of head injury, alcohol abuse or serious neurological or physical disease. None of the patients had been hospitalized in the past six months and all were relapsing multiepisode patients able to live in the community on maintenance AP therapy. The mean age was 32.60 years (SD 7.48), and educational level (number of successfully achieved classes) was 11.12 years (SD 2.85). Age at onset of symptoms was $23.00 \pm$ 5.07 and length of illness $10.00 \pm 6.65$ years. All were taking APs, and the mean chlorpromazine-equivalent dose $[15,16]$ was 403 (SD 195.09) at the time of the evaluation.

In order to avoid variables that could reduce the power of our investigation only patients on atypical or classical AP mono-therapy, clinically stabilized and well functioning in the community were selected. Patients were considered clinically stabilized if no single item of the Positive and Negative Syndrome Scale (PANSS) [17] exceeded the definition 'mild' of the symptom (no more than 3 in a range $1-7)$. Good functionality was considered satisfied if the subject reported 65 or more on the Global Assessment of Functioning Scale (G.A.F., D.S.M. - IV) in the past 6 months.

All participants provided written informed consent after complete description of the study, in accordance with the local university institutional review board (Ethic Committee A.U.S.L. 4 L'Aquila)

\section{Procedure}

All subjects undertook two separate WCST sessions (128 cards). The first administration was along the standard instructions as described by Heaton [18]; at the second test administration, one hour after the first one, the subjects were also required to 'verbally express' the matching criterion before the card sorting. The performance was considered poor or successful on the basis of the number of categories achieved: poor if less o equal 3, successful if 4 or more according to previous studies $[18,6,10]$. Three possible kinds of performance were considered: a) good performance if the subject achieved 4 or more categories both at the first and second administration; b) remediable performance if the subject reported a poor performance at the first but good at the second one; c) poor performance at both the administrations.

WCST indexes used in the subsequent calculations are the number of completed categories (CC), perseverative errors (PE), total errors (TE) and unique errors (UR). 
Table I: Distribution and WCST performance under standard or modified administration (verbalization) of the studied sample.

\begin{tabular}{|c|c|c|c|c|}
\hline \multirow[b]{2}{*}{ WCST indexes } & \multicolumn{4}{|c|}{ WCST Performance } \\
\hline & Total sample $(n=63)$ & Good $(n=40)$ & Poor $(n=16)$ & Remediable $(n=7)$ \\
\hline \multicolumn{5}{|l|}{ Categories Achieved } \\
\hline Standard adm. & $3.9 \pm 2.4 \#$ & $5.6 \pm 0.9$ & $0.6 \pm 0.9 *$ & $2.0 \pm 1.4 \S$ \\
\hline Verbalization & $4.6 \pm 2.0$ & $5.8 \pm 0.4$ & $1.3 \pm 0.9$ & $5.4 \pm 0.7$ \\
\hline \multicolumn{5}{|l|}{ Perseverative Errors } \\
\hline Standard adm. & $17.4 \pm 11.9 *$ & $14.4 \pm 11.2 \#$ & $23.8 \pm 11.6^{* *}$ & $20.0 \pm 12.0$ \\
\hline Verbalization & $13.0 \pm 17.6$ & $4.8 \pm 9.2$ & $34.2 \pm 19.0$ & $11.0 \pm 9.5$ \\
\hline \multicolumn{5}{|l|}{ Total Errors } \\
\hline Standard adm. & $30.9 \pm 15.8 \S$ & $23.7 \pm 13.8 \#$ & $43.6 \pm 10.8 \S$ & $42.8 \pm 11 . I^{*}$ \\
\hline Verbalization & $23.6 \pm 23.6$ & $11.6 \pm 15.6$ & $53.4 \pm 16.0^{\circ}$ & $23.9 \pm 15.1$ \\
\hline \multicolumn{5}{|l|}{ Unique Errors } \\
\hline Standard adm. & $1.9 \pm 4.4^{*}$ & $1.1 \pm 2.2^{*}$ & $1.8 \pm 3.1$ & $6.7 \pm 10.6$ \\
\hline Verbalization & $0.8 \pm 3.0$ & $0.1 \pm 0.4$ & $1.6 \pm 5.0$ & $2.8 \pm 4.5$ \\
\hline
\end{tabular}

Paired t-tests Standard adm vs Verbalization: $* P<0.05$; $* * P<0.0$ I; $\S P<0.005$; $\# P<0.0005$

\section{Statistical analysis}

Two-way ANOVA with remediation effect (standard administration vs. verbalization) as within subjects factor and atypical or classical AP therapy, as between subjects factor, was performed separately on the WCST indexes as dependent variables. Chi square and Student t-test were used when necessary. All analyses yielding a $p$ value of less than 0.05 were considered significant.

\section{Results}

Forty of the 63 subjects $(63.5 \%)$ were good performers and 23 poor performers; of these latter 7 were the subjects who remediated (the $30.4 \%$ of the poor performers at standard WCST administration).

WCST performance and distribution of the total sample along the 'remediation pattern' (Good, Remediable and Poor) is reported in the Table 1. Both Good and Remediating subjects improved their performance while Poor performers at both WCST administrations worsened in terms of an increase of perseverative and total errors.

33 (52.4\%) patients were taking atypical Aps. More males than females were taking classical APs (83.3\% of subjects with classical AP treatment vs. $60.6 \%$ of subjects on atypicals; Chi-Square $=3.97$, d.f. $=1, P<0.05$ ). No differences were seen in total PANSS score between the 2 groups (classical APs $72.6 \pm 22.7$, atypical $76.00 \pm 18.90$ ).

When further stratification was made on the basis of atypical or classical AP therapy, more poor performers not remediating were seen in the sample with classical APs (68.75\% of the poor performers) while remediators were only present in the subgroup with atypical APs (ChiSquare $=9.28$, d.f. $=2, P<0.01$ for $2 \times 3$ contingency table). The WCST performances stratified by kind of response to the standard and modified WCST administration and AP treatment are reported in the Table 2.

In the total sample, subjects with atypical APs showed less perseverative and total errors than those on classical, both at standard or modified administration; moreover subjects assuming atypical APs only, significantly reduced perseverative and total errors with verbalization.

When the kind of response to the modified administration was examined, an increase of perseverative and total errors in poor performers was seen among the subjects on classical APs only (interaction $\mathrm{F}=5.50, P<0.05$ ). A similar interaction, without treatment or verbalization effect, with an increase of unique errors in subjects on atypicals was also seen.

\section{Discussion}

Subjects on atypical AP treatment reported a better executive function pattern in terms of WCST performance than those on classical one. Moreover with the modified WCST administration, remediation does occur in the atypical group only, while poor performers on classical Aps did worsen their performance.

Our observation is in agreement with the results from Reeder et al. [19] study on executive skills reporting that people on atypical AP medication show greater improvement in working memory than those on classical; the greatest benefit was gained by those who both received Cognitive Remediation Therapy (CRT) and were prescribed atypical antipsychotic medication. On the other hand cognitive and psychosocial improvement from Cognitive Enhancement Therapy (CET) was found unrelated to the type of AP medication received [20]. This study was not however focused on executive functions evaluation 
Table 2: Distribution and WCST performance under standard or modified administration (verbalization) of subjects on atypical and classical AP treatment.

\begin{tabular}{|c|c|c|c|c|c|c|c|}
\hline \multirow[t]{3}{*}{ WCST indexes } & \multicolumn{7}{|c|}{ WCST performance } \\
\hline & \multicolumn{2}{|c|}{ Total sample } & \multicolumn{2}{|c|}{ Good } & \multicolumn{2}{|c|}{ Poor } & \multirow{2}{*}{$\begin{array}{c}\text { Remediable } \\
\begin{array}{c}\text { Atypical AP } \\
(n=7)\end{array}\end{array}$} \\
\hline & $\begin{array}{l}\text { Atypical AP } \\
(n=33)\end{array}$ & $\begin{array}{c}\text { Classical AP } \\
(n=30)\end{array}$ & $\begin{array}{l}\text { Atypical AP } \\
(n=21)\end{array}$ & $\begin{array}{l}\text { Classical AP } \\
(\mathrm{n}=19)\end{array}$ & $\begin{array}{c}\text { Atypical AP } \\
(n=5)\end{array}$ & $\begin{array}{c}\text { Classical AP } \\
(n=1 I)\end{array}$ & \\
\hline \multicolumn{8}{|l|}{ Categories Achieved a, e, i } \\
\hline Standard adm. & $4.1 \pm 2.4 \S$ & $3.8 \pm 2.4^{*}$ & $5.8 \pm 0.5$ & $5.4 \pm 1.2$ & $0.0 \pm 0.0$ & $1.0 \pm 1.0$ & $2.0 \pm 1.4 \S$ \\
\hline Verbalization & $5.0 \pm 1.9$ & $4.2 \pm 2.1$ & $5.9 \pm 0.4$ & $5.8 \pm 0.5$ & $0.8 \pm 1.3$ & $1.5 \pm 0.6$ & $5.4 \pm 0.7$ \\
\hline \multicolumn{8}{|l|}{ Perseverative Errors b, f, I } \\
\hline Standard adm. & $13.8 \pm 9.0$ & $21.4 \pm 13.5$ & $10.5 \pm 6.6 \#$ & $18.7 \pm 13.6 \S$ & $19.2 \pm 7.8$ & $26.0 \pm 12.7 \S$ & $20.0 \pm 12.0$ \\
\hline Verbalization & $6.9 \pm 8.7$ & $19.6 \pm 22.2$ & $2.7 \pm 5.0$ & $7.1 \pm 12.1$ & $18.8 \pm 6.5$ & $41.3 \pm 18.7$ & $11.0 \pm 9.5$ \\
\hline \multicolumn{8}{|l|}{ Total Errors c, g, m } \\
\hline Standard adm. & $27.1 \pm 13.9 \#$ & $35.0 \pm 17.0$ & $19.1 \pm 8.3 \#$ & $28.8 \pm 16.9 * *$ & $38.8 \pm 8.9$ & $45.8 \pm 11.2^{*}$ & $42.8 \pm 11.1 *$ \\
\hline Verbalization & $17.3 \pm 17.6$ & $30.5 \pm 27.5$ & $8.1 \pm 9.7$ & $15.4 \pm 19.8$ & $46.6 \pm 10.0$ & $56.6 \pm 17.6$ & $23.9 \pm 15.1$ \\
\hline \multicolumn{8}{|l|}{ Unique Errors d, h, n } \\
\hline Standard adm. & $2.3 \pm 5.6$ & $1.5 \pm 2.4 \S$ & $1.0 \pm 2.4$ & $1.2 \pm 1.9 *$ & $1.6 \pm 3.5$ & $1.9 \pm 3.1$ & $6.7 \pm 10.6$ \\
\hline Verbalization & $1.5 \pm 4.1$ & $0.1 \pm 0.3$ & $0.2 \pm 0.6$ & $0.0 \pm 0.2$ & $5.0 \pm 8.6$ & $0.1 \pm 0.5$ & $2.8 \pm 4.5$ \\
\hline
\end{tabular}

2-way mixed ANOVAs

Total sample

AP treatment effect $(A):$ a $F=1.0 \mathrm{NS} ;{ }^{b} F=10.7 P<0.0025 ; \mathrm{c} F=5.7 P<0.025 ;{ }^{d} F=1.8$ NS.

Remediation effect $(B):{ }^{a} F=14.6 P<0.0005 ;$ b $F=5.6 P<0.025 ; c F=10.3 P<0.0025 ;{ }^{d} F=5.6 P<0.025$.

$A \times B$ interaction: ${ }^{a} F=1.51 \mathrm{NS} ; \mathrm{b} F=2.04 \mathrm{NS} ;{ }^{c} \mathrm{~F}=1.43 \mathrm{NS} ;{ }^{\mathrm{d}} \mathrm{F}=0.47 \mathrm{NS}$

Good performers

AP treatment effect (A): e $F=1.5 \mathrm{NS} ; \mathrm{f} F=5.5 P<0.025 ; g \mathrm{~F}=4.8 P<0.05 ; \mathrm{h} \mathrm{F}=0.0 \mathrm{NS}$.

Remediation effect (B): ${ }^{\mathrm{e}} \mathrm{F}=2.9 \mathrm{NS} ; \mathrm{f}^{\mathrm{F}} \mathrm{F}=35 . \mathrm{I} P<0.0005 ; \mathrm{g} F=26.4 \mathrm{P}<0.0005 ;$ h $\mathrm{F}=7.0 P<0.025$.

$\mathrm{A} \times \mathrm{B}$ interaction: $\mathrm{e} \mathrm{F}=\mathrm{I} . \mathrm{I} \mathrm{NS} ;{ }^{\mathrm{f}} \mathrm{F}=\mathrm{I} .3 \mathrm{NS} ; \mathrm{g} F=0.2 \mathrm{NS} ;{ }^{\mathrm{h}} \mathrm{F}=0.4 \mathrm{NS}$

Poor performers

AP treatment effect $(\mathrm{A})$ : $^{\mathrm{i}} \mathrm{F}=4.9 \mathrm{p}<0.05 ; \mathrm{I} \mathrm{F}=4.6 \mathrm{P}<0.05 ; \mathrm{m} \mathrm{F}=1.7 \mathrm{NS} ; \mathrm{n} \mathrm{F}=1.4 \mathrm{NS}$

Remediation effect $(B):{ }^{i} F=6.4 P<0.025 ; ' \mathrm{~F}=4.9 P<0.05 ; \mathrm{m} F=7.6 P<0.025 ;{ }^{n} \mathrm{~F}=0.6 \mathrm{NS}$.

$A \times B$ interaction: ${ }^{i} F=0.2 \mathrm{NS} ;{ }^{~} \mathrm{~F}=5.5 P<0.05 ; \mathrm{m} F=0.2 \mathrm{NS} ;{ }^{\mathrm{n}} \mathrm{F}=6.0 P<0.05$

Paired t-tests Standard adm vs Verbalization: $* P<0.05$; ** $P<0.01$; $§ P<0.005$; $P<0.0005$

but neuropsychological composites and cognitive style index are reported. Similarly in a randomized controlled study of the effects of a cognitive remediation program on adolescents with early onset schizophrenia, no significant differences were found between the subjects on classical and atypical Aps [21].

Moreover we replicated and expanded our previous observations $[10,11]$ in a new larger independent sample, although the percentage of subjects with good or remediating performance is remarkably different (good performers: present study $63.5 \%$, previous study $26.9 \%$; remediating subjects: present study $30.4 \%$, previous study $63.2 \%$ ) [11]. This could be due to the selection bias, because we studied subjects with good functionality only.

The naturalistic assignment of medication does not permit to draw definitive conclusions about the effect of medication on cognitive performance and its interaction with cognitive remediation potential. Because of the design of the study we do not state a priori explicit and research criteria for AP treatment assignments. This deci- sion has been left on clinical judgment. We cross-sectionally studied and compared the two groups.

However medication type might be not strictly correlated with clinical features of the disorder (i.e. development of the illness, treatment failures, patient's cognitive profile etc.): it could be possible that patients with more recent onset have been treated with atypical APs because these were more widely available, while older clinically stable patients remained on classical APs. In other words, criteria leading to the AP treatment choice could be influenced by socioeconomical and historical factors too. These factors are well beyond the scope of this article.

Another potential limitation could be due to fixed order WCST administrations: the remediation could reflect merely practice effect instead of an effect of verbalization. However there is a dearth of literature on cognitive test practice effects in schizophrenia, likely because of the scarce possibility of improvement [22]. One study [23] reported no evidence of practice effect, repeating executive tests after 3 weeks, in stable treatment-resistant patients 
treated with clozapine. Stratta et al. [10] administering four times WCST in two days did not observe improvement in patients on classical AP medication. Harvey et al. [24] found that the degree of improvement with practice was greater in patients administered an atypical medication than in those given typical medication. However the possibility to achieve practice effect, previously limited by classical AP treatment, could also been an important result. The restoration of a practice effect is real advantage although does not represent actual procognitive effectiveness $[25,26]$. Follow up- studies are needed to better clarify the meaning of the 'remediation'.

\section{Conclusion}

Although we are still far from the point of a meaningful integration of cognitive findings with AP treatment outcome, results from neuropsychological assessment could provide guidance to the patient's management. We could hypothesize that patients who do not remediate, even if in a state of clinical response to classical AP treatment, could have a trial with atypicals to evaluate a chance of cognitive improvement. On the other hand subjects who do not show improvement could benefit from a different attentional training using rehabilitation methodologies more weighted on procedural learning or practice effect [27].

Improvement in cognitive functioning is one of the most important clinical targets in the treatment of schizophrenia [28]. In the cognitive 'puzzle', we propose that the remediation 'piece' is associated with better cognitive functioning and atypical AP treatment. We need further study to evaluate how these three variables are connected and what kind of clinical predictions they offer.

\section{Authors' contributions}

$\mathrm{AR}$ and ES conceived and designed the study, were involved in the revisions. AT, FS and RC collected neurocognitive test data and co wrote first draft. ED and PS advised on statistical analysis, helped to write the corresponding sections and drafted the manuscript. All authors read and approved the final manuscript.

\section{Acknowledgements}

Financial support: This study has been conducted with a financial grant of Ministero dell'Università e della Ricerca Scientifica e Tecnologica PRIN 2001 prot. 2001064198_002.

\section{References}

I. Sharma T, Antonova L: Cognitive function in schizophrenia, functional consequences, and future treatment. Psychiatr Clin N Am 2003, 26:25-40.

2. Mueser KT, Mc Gurk SR: Schizophrenia. Lancet 2004, 363:2063-2072

3. Rund BR, Borg NE: Cognitive deficits and cognitive training in schizophrenic patients: a review. Acta Psychiatr Scand 1999, 100:85-95.

4. Wykes T: Cognitive rehabilitation and remediation in schizophrenia. In Cognition in schizophrenia: impairments, importance and treatment strategies Edited by: Sharma T, Harvey P. Oxford University Press, New York; 2000:332-35I.

5. Wykes $T$, van der Gaag M: Is it time to develop a new cognitive therapy for psychosis - cognitive remediation therapy (CRT)? Clin Psychol Rev 200I, 2I(8): I227-I 256.

6. Perry W, Potterat EG, Braff DL: Self-monitoring enhances Wisconsin Card Sorting Test performance in patients with schizophrenia: Performance is improved by simply asking patients to verbalize their sorting strategy. J Int Neuropsychol Society 200I, 7:344-352.

7. Rossel SL, David AS: Improving performance on the WCST: variations on the original procedure. Schizophr Res 1997, 28:63-76.

8. Sarfati $Y$, Hardy-Baylé MC, Brunet E, Widlocher D: Investigating theory of mind in schizophrenia: influence of verbalization in disorganized and non-disorganized patients. Schizophr Res 1999, 37:183-190.

9. Sarfati Y, Passarieux C, Hardy-Baylé MC: Can verbalization Remedy the Theory of Mind Deficit in Schizophrenia? Psychopathology 2000, 33:246-25I.

10. Stratta P, Mancini F, Mattei P, Rossi A: Information processing strategy to remediate Wisconsin Card Sorting Test performance in schizophrenia: a pilot study. Am J Psychiatry 1994, 151:915-918.

II. Stratta P, Mancini F, Mattei P, Daneluzzo E, Bolino F, Rossi A: Cognitive remediation of Wisconsin Card Sorting Test performance in schizophrenia: a controlled study. Psychopathology 1997, 30:59-66.

12. Sheng Ran Mao, Yu-Hai Chen: Cognitive enhancement therapy for schizophrenia. Lancet 2004, 364:2 I 63-2। 65.

13. Harvey PD, Keefe RSE: Studies of cognitive change in patients with schizophrenia following novel antipsychotic treatment. Am J Psychiatry 200I, I 58:176-184.

14. Spitzer RL, Williams JBW, Gibbon M: Structured Clinical Interview for DSM-III-R (Scid) New York State Psychiatric Institute, Biometrics Research, New York; 1987.

15. Kessler KA, Waletzky JP: Clinical use of the antipsychotics. Am J Psychiatry 1981, I38:202-209.

16. Woods SW: Chlorpromazine equivalent doses for the newer atypical antipsychotics. J Clin Psychiatry 2003, 64:663-667.

17. Kay SR, Fiszbein A, Opler LA: The positive and negative syndrome scale (PANSS) for schizophrenia. Schizophr Bull 1987, I3:26I-276.

18. Heaton RK: Wisconsin Card Sorting Test manual Psychological Assessment Resources, Odessa; 198I.

19. Reeder C, Newton E, Frangou S, Wykes T: Which executive skills should we target to affect social functioning and symptom change? A study of a cognitive remediation therapy program. Schizophr Bull 2004, 30(I):87-100.

20. Hogarty GE, Flesher S, Ulrich R, Carter M, Greenwald D, Pogue-Geile $M$, others: Cognitive Enhancement Therapy for Schizophrenia. Arch Gen Psychiatry 2004, 61 :866-876.

21. Ueland T, Rund BR: A controlled randomized treatment study: the effects of a cognitive remediation program on adolescents with early onset psychosis. Acta Psychiatr Scand 2004, 109:70-74.

22. Beglinger LJ, Ahmed S, Derby MA, Siemers E, Fastenau PS, CrawfordMiller J, others: Neuropsychological practice effects and change detection in people with schizophrenia. Schizophr Res 2003, 62:191-4

23. Hagger C, Buckley P, Kenny JT, Friedman L, Ubogy D, Meltzer HY: Improvement in cognitive functions and psychiatric symptoms in treatment-refractory schizophrenic patients receiving clozapine. Biol Psychiatry 1993, 34:702-12.

24. Harvey PD, Moriarty PJ, Serper MR, Schnur E, Lieber D: Practicerelated improvement in information processing with novel antipsychotic treatment. Schizophr Res 2000, 46:139-1 48.

25. Carpenter WT, Gold JM: Another view of therapy for cognition in schizophrenia. Biol Psychiatry 2002, 51 : 969-7I.

26. Bédard MA, Scherer H, Delorimier J, Stip E, Lalonde P: Differential effects of D2- and D4-bocking neuroleptics on the procedural learning of schizophrenic patients. Can J Psychiatry 1996, 4 I (7 suppl I):S2I-S24.

27. Fuller TR, Oka M, Liberman RP, et al: A hybrid supported employment program for persons with schizophrenia in Japan. Psychiatric Serv 2000, 5 I (7):864-866. 
28. MATRICS: Measurement And Treatment Research to Improve Cognition in Schizophrenia. [http://www.mat rics.ucla.edu/].

\section{Pre-publication history}

The pre-publication history for this paper can be accessed here:

http://www.biomedcentral.com/1471-244X/6/3/prepub

Publish with Bio Med Central and every scientist can read your work free of charge

"BioMed Central will be the most significant development for disseminating the results of biomedical research in our lifetime. " Sir Paul Nurse, Cancer Research UK

Your research papers will be:

- available free of charge to the entire biomedical community

- peer reviewed and published immediately upon acceptance

- cited in PubMed and archived on PubMed Central

- yours - you keep the copyright 